\title{
Germination and Vegetative Growth of Selected Hybrid Tomato (Lycopersicum esculentum Mill.) Cultivars under Hot and Wet Environmental Conditions in Rivers State Nigeria
}

\author{
Joy Aniso ${ }^{1}$, Elsie Ihuakwu Hamadina ${ }^{1}$, Mohammed Kurama Hamadina ${ }^{2}$ \\ ${ }^{1}$ Crop and Soil Science Department, Faculty of Agriculture, University of Port Harcourt, Port Harcourt, Nigeria \\ ${ }^{2}$ Biogeochem Associates Ltd, Port Harcourt, Nigeria
}

Email addresses:

elsieile@yahoo.com (E. I. Hamadina), anisoebitari@yahoo.conm (J. Aniso), m.hamadina@biogeochem.com (M. K. Hamadina)

To cite this article:

Joy Aniso, Elsie Ihuakwu Hamadina, Mohammed Kurama Hamadina. Germination and Vegetative Growth of Selected Hybrid Tomato (Lycopersicum esculentum Mill.) Cultivars under Hot and Wet Environmental Conditions in Rivers State Nigeria. Journal of Plant Sciences. Vol. 3, No. 2, 2015, pp. 99-105. doi: 10.11648/j.jps.20150302.19

\begin{abstract}
Tomato (Lycopersicum esculentum Mill.) is a commonly cultivated vegetable crop; however, there is a dearth of information on germination and vegetative growth of tomato cultivars under the hot and wet humid tropical conditions of the Niger Delta in Nigeria. Although several hybrids exist, there are no known cultivars selected for cultivation under the Niger Delta conditions. The objectives of this study were to evaluate the germination and vegetative growth of five tomato cultivars under hot and wet conditions, and to identify potentially suitable cultivar(s) for the Niger Delta. The tomato cultivars tested included a high-performing non-hybrid cultivar common to northern Nigeria (Roma Vf), hybrids bred for hot and wet environment (AVTO9803 and AVTO9001) and hybrids bred for cool/dry environment (AVTO1001 and AVTO1006). Germination tests were conducted and the cultivars were grown under two conditions during the rainy season: in the open field under direct rain, and in a glasshouse with regular watering to field capacity. Results show that Roma Vf had the poorest percent germination (19\% in cold test) by 6 days after sowing, while the best performing cultivars in terms of seed quality were AVTO9803 and AVTO9001. In both field and glasshouse environments, Roma Vf grew significantly taller, with more nodes, high leaf numbers, leaves and greater leaf lengths than the exotic cultivars (with the exception of AVTO9001 and sometimes AVTO9803). The cultivar AVTO9803 performed best under the extremely hot conditions $\left(\geq 35^{\circ} \mathrm{C}\right)$ in the glasshouse than on the field. This suggests that the two hybrids (AVTO9803 and AVTO9001) and Roma Vf are potentially cultivable under the hot/wet conditions, but Roma Vf would require extra care due to its poor germination rates.
\end{abstract}

Keywords: Tomato Hybrids, Heat Tolerance, Humid Tropics

\section{Introduction}

Tomato (Lycopersicum esculentum Mill.) is an important tropical crop with many nutritional and health benefits for children, adults and the elderly. Tomato contains carotenoids [1], which are the main source of lycopene, the red coloring pigment in tomato. Lycopene is an antioxidant with high biological activity [2, 3]. Also, tomato has high contents of vitamins (B, C, and E) and folic acid, therefore, play important roles in human fertility, food metabolism, and maintenance of neurological system, immune system, and prevention of cancer [3]. Also, the high amounts of potassium and magnesium contained in tomatoes protects the human heart and helps overcome symptoms of stress and muscular cramps [3].

Tomato is one of the world's major food crop [4] as well as one of the most widely researched and commercially produced vegetable [5]. However, its cultivation is largely confined to environments, or seasons, that are cool and dry with some cultivation in hot and dry seasons $[6,7]$. Thus, the most commonly available tomato cultivars are adapted to cool and dry environments [6]. On the other hand, cultivation in hot and wet season is rare, being faced with both heat- and excess water-related challenges, resulting in unattractive fruit 
yields and income [8]. Consequently, areas with long hot and wet season must restrict field production of tomato to once per year. To meet demands during off season, tomatoes have to be transported over long distances demand, which in turn leads to high price of fresh tomato, and limited consumption of such an important vegetable.

The hot and wet season is the longest season in many high rainfall humid tropical areas such as Niger Delta in Nigeria. In Nigeria therefore, commercial tomato production is restricted to the North of the country with a savannah agroecology and a few Southern states with moist savannah agroecology [8].With a population of 160 million people and a production of 1,701,000 tones of tomato per annum Nigeria produces only $5 \%$ of what is produced by China, and $12 \%$ of that produced in the United States of America [9], and Nigeria's demand for fresh tomato surpasses its supply particularly during offseason[10].Generally, the constraints to tomato production in Nigeria include the restriction of tomato production to a particular season, resulting in periods of abundance and scarcity, which in turn leads to high fresh fruit price, and the cultivation of exotic cultivars that are not well adapted to local conditions [7]. Other constraints are poor seed quality, misuse of fertilizer, inadequate land, poor transport system, and pest and disease problems, particularly during the rainy season [11].

The most commonly cultivated tomato varieties are low yielding and susceptible to common tropical diseases such as fusarium wilt, gray leaf spot, tomato yellow leaf curl virus (TYLCV), and bacterial blight [6, 7,]. Afolami and Ayinde, 2001 [11] reported that spoilage of tomato fruit can be reduced in Nigeria by limiting travelling time and distance or improving transportation network, because tomato is highly perishable deteriorating rapidly during handling and storage due to natural ripening processes, physiological break down associated with water loss and respiration, temperature injury, physical damage or invasion by micro-organism [12].

Earlier works have addressed tomato problems by developing methods for protecting hot and dry season tomato crops from insect and disease [11]. Recent progress in research has led to the identification of five moderately disease resistant cultivars to replace the low yielding, disease-susceptible cultivars grown during the hot and dry season in Nigeria [13].In order to significantly increase the productivity and supply of fresh tomatoes, their cultivation during the long hot and wet season is necessary. However, since most varieties are not adapted to the hot and wet season, there is need for careful selection of cultivars that are adapted to hot and wet conditions. Such cultivars need to exhibit desirable characteristics such as good germinating, fast growing, high yielding and resistant to major tropical diseases that. Hanson et al., 2001 [6] have emphasized that the factors to consider when selecting the best cultivar for an environment are adaptation of cultivar to season, disease resistance, plant habit and fruit type. The cultivation of tomato cultivars that are adapted to hot and wet season has not been reported in Nigeria. Nevertheless a few tomato cultivars that can grow during hot and wet seasons have been breed for by the World Vegetable Centre (AVRDC) in Taiwan. Therefore, this study sought to assess seed quality and field performance of exotic hot and wet season tomato cultivars under the hot and wet conditions of Port Harcourt in the Niger Delta region of Nigeria to identify those that are potentially suitable for cultivation in the region.

\section{Materials and Methods}

\subsection{Tomato Varieties Tested}

Five tomato cultivars were assessed in this study. Four out of the five cultivars were exotic hybrids (AVTO9803, AVTO9001, AVTO1002 and AVTO1006) of Tomato (Lycopersicum esculentum). They were purchased from the World Vegetable Centre, Shanhua, Tainan 74151 Taiwan. AVTO9803 and AVTO9001 are bred to grow under a hot and wet seasons while AVTO1002 and AVTO1006 are bred to grow under hot and dry seasons. The characteristics of these varieties as well as their disease reactions are shown in Table 1.The fifth cultivar was Roma Vf, which was purchased from Jos, Nigeria. Roma Vf is a non-hybrid open pollinated cultivar that has gone through steady improvement. It is about the most widely grown non-hybrid variety of tomato, adaptable to different heat and moisture conditions (http://www.seedaholic.com/tomato-plum-roma-Vf.html). In Nigeria, it is the most common cultivar of tomato cultivated on small and commercial farms in the North, which is the main center of tomato production in the country. It is for these reasons that Roma Vf was chosen as local check/control in this study.

Table 1. Characteristics of the selected tomato varieties.

\begin{tabular}{|c|c|c|c|c|c|}
\hline & ROMA Vf & AVTO1002 & AVTO9803 & AVT09001 & AVT01006 \\
\hline Target environment & $\mathrm{NI}$ & Hot/ dry & Hot/wet & Hot/wet & Hot/dry \\
\hline Heat tolerance & NI & Good & Excellent & Good & Moderate \\
\hline Maturity & $\mathrm{NI}$ & Medium & Early & Medium & Medium \\
\hline Leaf blight & NI & $\mathrm{S}$ & $\mathrm{S}$ & $\mathrm{S}$ & $\mathrm{S}$ \\
\hline Grey leaf spot & NI & $\mathrm{S}$ & $\mathrm{S}$ & $\mathrm{S}$ & $\mathrm{S}$ \\
\hline Bacterial wilt & $\mathrm{NI}$ & $\mathrm{S}$ & $\mathrm{R}$ & $\mathrm{R}$ & MR \\
\hline Tomato yellow leaf curl & NI & Ty, $1,2,3$ & $\mathrm{~S}$ & $\mathrm{~S}$ & Ty, $1,2,3$ \\
\hline Tobacco mosaic virus & $\mathrm{NI}$ & $\mathrm{R}$ & $\mathrm{R}$ & $\mathrm{R}$ & $\mathrm{R}$ \\
\hline Fruit $\mathrm{Wt}(\mathrm{g})$ & 70 & 120 & 55 & 100 & 110 \\
\hline
\end{tabular}

$\mathrm{NI}=$ no information available; $\mathrm{S}=$ susceptible; $\mathrm{R}=$ resistant; $\mathrm{MR}$ : moderately resistant 


\subsection{Seed Quality Assessment}

To assess the seed quality of each variety and predict their germination performance on the field, warm and cold germination tests were carried out. In both germination tests, the selected cultivars constituted the experimental treatment.

\subsubsection{Warm Germination Test}

One hundred (100) seeds of each cultivar were placed on two layers of damp paper towels in a seed tray. The seeds were then covered with damp paper towel and the seeds plus tray was placed in a transparent poly-ethylene bag. All covered seed trays were placed by a window to allow sunlight (but not direct sunlight) to warm up the seeds. The seeds were observed on the third day, sixth and ninth day after sowing for seed germination.

\subsubsection{Cold Germination Test}

One seed/cultivar was sown in $5 \mathrm{ml}$ plastic cups filled with sterilized soil and there were 75 cups/ variety. The seeds were allowed to germinate under a transparent roof shade. Observation was made daily for seed germination.

\subsection{Vegetative Growth Performance}

\subsubsection{Growth Environment Conditions}

Four cultivars (AVTO1002, AVTO9803, AVTO9001 and Roma Vf) were grown in pots on the field and in a glasshouse in two separate experiments. On the field, pregerminated seedlings were transplanted into $7.5 \mathrm{~L}$ plastic pot filled with top soil. Planting was done during the rainy season in the month of August when the weather was hot $\left(>25{ }^{\circ} \mathrm{C}\right.$ but $<35^{\circ} \mathrm{C}$ for most part of the day) and wet, and the plants were rain-fed. Watering was done regularly in the glasshouse to keep potted soil moist. In the glasshouse, planting was also done in the month of August. Temperature in the glasshouse remained high $\geq 40{ }^{\circ} \mathrm{C}$ through the night and early morning hours, but humidity was low. During the day extreme heat condition was regulated using heavy-duty fans that come on automatically when the temperature in the glasshouse went above $27^{\circ} \mathrm{C}$.

\subsubsection{Growth Data Collection}

Data collection began one week after transplanting. In each environment, three plants per treatment per replicate were randomly selected for weekly data collection. Plant height was taken from the base of the main stem to the tip using a meter rule $(\mathrm{cm})$.Number of leaves per plant was monitored by counting all leaves on each plant. Number of nodes per plant was assesses by counting all the nodes on each plant. Leaf length and width were measured on five randomly selected leaves. Leaf length (in $\mathrm{cm}$ ) was measured from the base of the leaf (point of attachment of the petiole to the leaf) to the tip of the leaf while leaf width was measured along the widest part of the leaves. At the end of the study, i.e., at the end of vegetative growth, dry matter accumulation was assessed. This was done by sampling, randomly, two plants per variety per replicate. The plants were carefully removed from the pots, cleaned and separated into their component parts. Fresh weight of these parts was taken using electronic weighing balance. The parts were then dried to constant weight for dry weight determination.

\subsection{Experiment Design and Data Analysis}

The germination experiments were arranged as Completely Randomized Design (CRD). In the warm germination experiment, there were 100 seeds per variety with each seed representing a replicate. Duration to germination was estimated as duration from sowing to emergence of cotyledon while the proportion of seeds that germinated in days after the start of the experiment was estimated as a percentage of the total number of seeds sown. In the cold germination experiment, there were four treatments (varieties), with three replications and each plot was made up of 25 plants. The vegetative growth experiment (field-pot experiment and glasshouse experiment) were arranged as Completely Randomized Design (CRD) with four treatments (varieties) replicated three times.

Data were analyzed using GENSTAT Discovery Edition $3{ }^{\circledR}$ statistical software. The Analysis of Variance (ANOVA), CRD option was used to analyze data on duration from sowing to emergence of cotyledon. All other data were analyzed using ANOVA, General Treatment Structure (no blocking) option. This option allowed the analysis to compare treatments in the two experiments. Treatment means were separated using the standard error of difference (SED). All the count data were transformed using square root transformation prior to data analysis.

\section{Results}

\subsection{Seed Quality Assessment}

\subsubsection{Percentage Seed Germination}

The warm germination test resulted in higher germination percentages than the cold germination test (Figure 1). In the warm test, less than $40 \%$ of Roma Vf seeds germinated 3 days after sowing compared with over $50 \%$ germination in the hybrids (Figure 1). Six days after sowing, about $90 \%$ of the hybrid seeds germinated, compared to $<70 \%$ for Roma Vf (Figure 1). Percent germination was highest in the hot and wet hybrid varieties, followed by the hot and dry hybrid varieties, while Roma Vf had the least (Figure 1). Three days after sowing, $<15 \%$ germination was observed in Roma Vf, the two hot and dry hybrids (AVT01006 and AVT00102) and one hot and wet hybrid (AVT09001). In contrast, 22\% germination was observed in AVT09803. By 6 DAS, percent germination increased marginally by $4 \%, 2 \%$ and $4 \%$ in AVT09803, AVT01006 and Roma Vf respectively. 


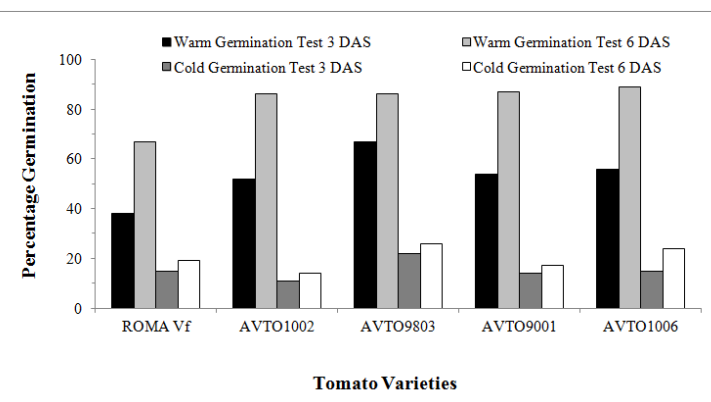

Figure 1. Germination (\%) in warm and cold germination tests.

\subsubsection{Duration from Sowing to Emergence of Cotyledon}

In the warm germination test, germination occurred between 4 and 6 days (d) after germination, and it was well synchronized. The hybrid cultivars germinated earlier $(\mathrm{p}=0.001)$ than the Roma Vf. The hot and wet season hybrids germinated about 2 days (d) earlier than Roma Vf. (Figure 2) while AVTO1002 (a hot and dry season hybrid) germinated about $1 \mathrm{~d}$ earlier than Roma Vf. In the cold germination study, the timing of germination was prolonged: up to $7 \mathrm{~d}$ in some cultivars, and erratic, although Roma Vf, AVTO9803 and AVTO1006 germinated earlier thanAVTO9001 and AVTO0102.

The results from the warm and cold germination show that three of the hybrid varieties (AVT09803, AVT01006, and AVT09001) can be consistent and do better than ROMA VF and AVT00102. The results also show that the hybrid varieties took shorter time to emerge and germinate, when compared to the local variety, and the percentages of seeds that germinated in the hybrids were higher than that of the local variety (ROMA Vf).In the warm germination, it took only 3 days after sowing for the hybrids to get to $50 \%$ germination, compared toonly $38 \%$ for the local variety. By 6 days after sowing the hybrids got to $75 \%$, while only $50 \%$ of ROMA Vf germinated by then.

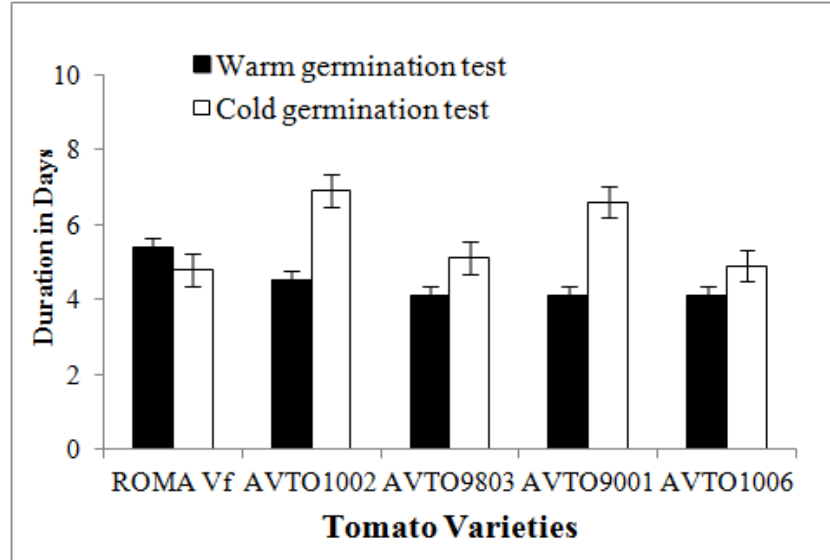

Figure 2. Duration from sowing to Germination

\subsection{Effect on Vegetative Growth}

\subsubsection{Plant Height}

The responses of the different varieties of tomato, with respect to plant height, showed that throughout the study, the local variety (ROMA Vf) grew significantly $(\mathrm{P} \leq 0.05)$ taller than each of the hybrid varieties. At 1 week after transplant (WAT), 2 WAT and 4 WAT, the environment and variety did not interact significantly, in terms of plant height. At 3 WAT, there was a significant environment $\mathrm{x}$ variety interaction (Figure 3). All varieties of tomato grown in the open field were generally taller than those grown in the glasshouse, except AVTO9803, which grew taller in the glasshouse (Figure 3).

\subsubsection{Plant Nodes}

Variety $\mathrm{x}$ environment interaction was not significantly different at 1 WAT, 2 WAT and 3 WAT. Also the mean number of nodes on the different varieties were not significantly different (Table 2). The number of nodes ranged from 1.7- 1.8, $1.9-2.1$ and $2.0-2.4$ at 1,2 and 3 WAT respectively. At 4 WAT and 5 WAT, significant differences were noticed in the number of nodes observed. At 4 WAP, the local cultivar (Roma Vf) and the hybrid AVTO9803 had higher number of nodes that the other hybrids under field conditions, while in the glasshouse, it was in the order: AVTO9803 $>$ ROMA Vf $=$ AVTO1002 $>$ AVTO9001 $(\mathrm{P} \leq$ 0.05).At 5 WAP, the hybrid ROMA Vf performed significantly $(\mathrm{P} \leq 0.05)$ better than the hybrids, except under Glasshouse conditions AVTO9803 (Table 2).

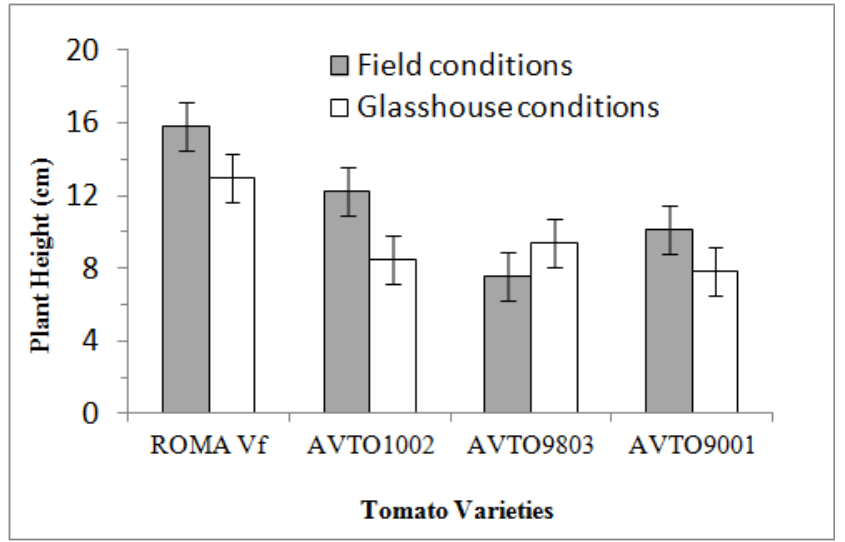

Figure 3. Environment $x$ variety interaction on plant height.

Table 2. Mean number of nodes (square root transformed) at 4 WAP.

\begin{tabular}{llllll}
\hline Environment & $\begin{array}{l}\text { Roma } \\
\text { Vf }\end{array}$ & AVTO1002 & AVTO09803 & AVTO9001 & Means \\
\hline \multicolumn{5}{l}{ Four Weeks After Planting } \\
Field & 2.677 & 2.260 & 2.527 & 2.239 & 2.405 \\
Glasshouse & 2.438 & 2.335 & 2.612 & 2.051 & 2.451 \\
Means & 2.558 & 2.297 & 2.527 & 2.239 & 2.357 \\
SE & 0.1153 & & & \\
& Five Weeks After Planting & & \\
Field & 2.844 & 2.308 & 2.303 & 2.492 & 2.487 \\
Glasshouse & 2.519 & 2.104 & 2.503 & 2.246 & 2.356 \\
Means & 2.681 & 2.206 & 2.428 & 2.369 & 2.421 \\
SED & 0.1130 & & & \\
\hline
\end{tabular}

\subsubsection{Number of Leaves}

At 1 WAT there was no significant interaction between environment and variety. Mean number of leaves in the local 
check/control was 2.6. AVTO9803 and AVTO9001 were not different from the control while the number of leaves in AVTO1002 (hybrid check) was significantly lower than that in the Roma Vf (local check) which was from $2.1-2.6$ and $2.7-3.4$ at 1, 2 respectively. At 3WAT, 4WAT and 5WAT, there were significant interactions between the environment $\mathrm{x}$ variety. Number of leaves was generally higher in the control than the other varieties. Also, the mean number of leaves was generally higher in varieties grown on the field than in the glasshouse, except for AVTO9803, which had more leaves in the glasshouse than on the field (Table 3).

Table 3. Mean number of Leaves of Tomato Cultivars.

\begin{tabular}{llllll}
\hline \multirow{2}{*}{ Environment } & $\begin{array}{l}\text { Roma } \\
\text { Vf }\end{array}$ & AVTO1002 & AVTO09803 & AVTO9001 & Means \\
\hline \multirow{5}{*}{ Field } & \multicolumn{7}{l}{ Three } & Weeks & After & Planting & & \\
Glasshouse & 5.17 & 4.16 & 3.45 & 4.15 & 4.23 \\
Means & 3.40 & 2.91 & 3.95 & 2.42 & 3.17 \\
SE & 4.29 & 3.54 & 3.70 & 3.29 & 3.70 \\
& 0.515 & & & & \\
Field & Four Weeks After Planting & & \\
Glasshouse & 5.71 & 4.31 & 4.01 & 4.07 & 4.25 \\
Means & 4.44 & 3.79 & 4.81 & 3.33 & 4.09 \\
SE & 5.07 & 4.31 & 4.01 & 4.07 & 4.31 \\
& 0.427 & & & & \\
Field & 7.41 & 5.36 & 4.98 & 6.05 & 5.95 \\
Glasshouse & 5.59 & 3.31 & 5.21 & 3.20 & 4.33 \\
Means & 6.50 & 4.34 & 5.09 & 4.62 & 5.14 \\
SED & 0.478 & & & & \\
\hline
\end{tabular}

\subsubsection{Length of Leaves}

The leaf length was greatly influenced by the environment and variety. Environment $\mathrm{x}$ variety interaction was not significant at 1 week after transplanting but the interaction was significant at 3 WAT, 4 WAT and 5 WAT. On the field and in the glasshouse, the leaf length of the local variety was the longest (3.0 and 2.6, field and glasshouse respectively), followed by AVT00102 and AVT09001. However, the mean leaf length for AVTO9803 was longer in the glasshouse than on the field (Table 4). Therefore leaf length was generally longer in the control than the other varieties and the varieties grew better in terms of length of leaf on the field than in the glasshouse except for AVTO9803, which grew longer leaf in the glasshouse than on the field.

\subsubsection{Width of Leaves}

There was significant interaction between environment and variety at1, 24 and 5 WAT. On the field, the leaf width for Roma Vf was wider (mean values were 1.2, 1.3, 1.6 and 1.6 at 1, 2, 4 and 5 WAT respectively) than that of the hybrids throughout the study. In the glasshouse, the leaf width for AVTO9803 was longer (mean values were1.3, 1.0, 1.4 and 1.4 at 1, 2, 4 and 5 WAT) than the other varieties (Table5).Therefore leaf width was generally longer in the control than the other varieties and the varieties grew better, in terms of width of leaf, on the field than in the glasshouse except for AVTO9803, which grew wider leaves in the glasshouse than on the field.
Table 4. Leaf length of the different tomato varieties.

\begin{tabular}{|c|c|c|c|c|c|}
\hline Environment & $\begin{array}{l}\text { Roma } \\
\text { Vf }\end{array}$ & AVTO1002 & AVTO09803 & AVTO9001 & Means \\
\hline & \multicolumn{5}{|c|}{ Four Weeks After Planting } \\
\hline Field & 3.040 & 2.836 & 2.614 & 2.787 & 2.820 \\
\hline Glasshouse & 2.639 & 2.401 & 2.732 & 2.275 & 2.512 \\
\hline Means & 2.839 & 2.618 & 2.675 & 2.530 & 2.666 \\
\hline \multirow[t]{2}{*}{ SE } & \multirow{2}{*}{\multicolumn{5}{|c|}{$\begin{array}{l}0.1565 \\
\text { Four Weeks After Planting }\end{array}$}} \\
\hline & & & & & \\
\hline Field & 3.136 & 2.982 & 2.780 & 2.836 & 2.933 \\
\hline Glasshouse & 2.927 & 2.518 & 2.972 & 2.375 & 2.698 \\
\hline Means & 3.031 & 2.750 & 2.876 & 2.605 & 2.816 \\
\hline \multirow[t]{2}{*}{ SED } & 0.149 & & & & \\
\hline & \multicolumn{5}{|c|}{ Five Weeks After Planting } \\
\hline Field & 3.309 & 2.989 & 2.842 & 2.955 & 3.022 \\
\hline Glasshouse & 2.973 & 2.456 & 3.020 & 2.365 & 2.708 \\
\hline Means & 3.144 & 2.733 & 2.929 & 2.660 & 2.868 \\
\hline SED & 0.1579 & & & & \\
\hline
\end{tabular}

Table 5. Leaf width of the various tomato varieties.

\begin{tabular}{llllll}
\hline Environment & $\begin{array}{l}\text { Roma } \\
\text { Vf }\end{array}$ & AVTO1002 & AVTO09803 & AVTO9001 & Means \\
\hline \multicolumn{5}{l}{ One Week After Planting } \\
Field & 1.231 & 1.240 & 1.100 & 1.070 & 1.183 \\
Glasshouse & 1.283 & 1.108 & 1.076 & 0.777 & 1.657 \\
Means & 1.262 & 1.240 & 1.088 & 0.926 & 1.124 \\
SE & 0.0729 & & & \\
& Two Weeks After Planting & & \\
Field & 1.280 & 1.123 & 1.086 & 1.213 & 1.176 \\
Glasshouse & 0.975 & 0.943 & 1.207 & 0.923 & 1.012 \\
Means & 1.128 & 1.034 & 1.147 & 1.068 & 1.094 \\
SE & 0.0954 & & & \\
Field & Four Weeks After Planting & & \\
Glasshouse & 1.569 & 1.482 & 1.373 & 1.376 & 1.450 \\
Means & 1.444 & 1.277 & 1.455 & 1.148 & 1.331 \\
SED & 1.507 & 1.380 & 1.414 & 1.262 & 1.390 \\
& 0.0778 & & & \\
Field & Five Weeks After Planting & & 1.457 \\
Glasshouse & 1.582 & 1.441 & 1.342 & 1.468 & 1.313 \\
Means & 1.506 & 1.251 & 1.457 & 1.117 & \\
SED & 0.0794 & 1.398 & 1.262 & 1.387 \\
\hline
\end{tabular}

\subsection{Dry Matter Content and Partitioning}

The leaf dry weight was higher for AVTO9001 > Roma Vf $>$ AVTO1002> AVTO9803 (Table 16).However, AVTO9001 () and Roma Vf are not significantly different. The stem dry weight was higher for AVTO9001 > Roma Vf > AVTO1002> AVTO9803 (Figure 4). However, AVTO9001 (1.82) and Roma Vf (1.38) are not significantly different. The root dry weight was higher for AVTO9001 > Roma Vf> AVTO1002> AVTO9803 (Table 16). However, AVTO9001 (0.27) and Roma Vf (0.24) are not significantly different. The total dry matter in the local check was $2.16 \mathrm{~g}$ (Figure 4). Total dry matter content was highest in AVTO9001 (2.75 g). Total dry matter was $1.4 \mathrm{~g}$ and $0.87 \mathrm{~g}$ for AVTO9803 and AVTO1002 respectively. In Roma Vf, 64, 25 and $11 \%$ of total dry matter was accumulated in the stem, root and leaf respectively. In AVTO9001, 67, 24 and $10 \%$ of total dry matter was accumulated in the stem, root and leaf respectively. Interestingly, AVTO9803 partitioned about the same quantity of its total dry matter to stem (44\%) and leaves (40\%). 


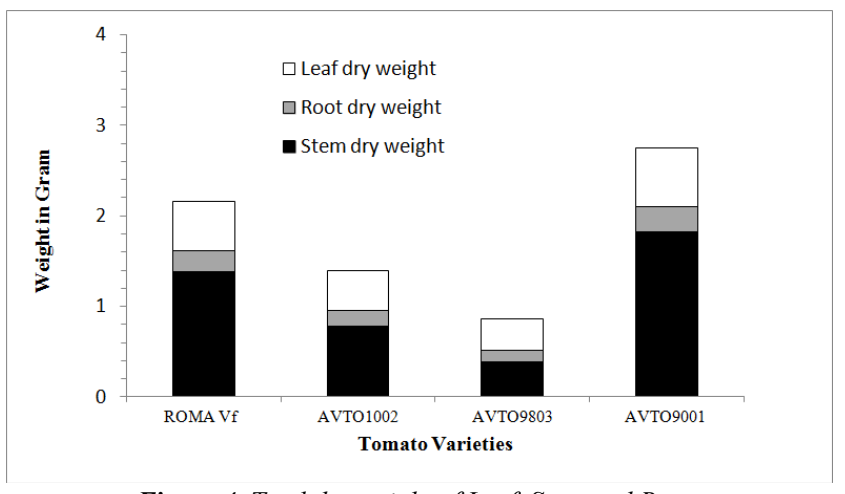

Figure 4. Total dry weight of Leaf, Stem and Root.

\section{Discussion}

This study has shown that variety is an important factor to be considered in the production of tomato as it determines the productivity of tomato plant under a defined growing environmental condition. In terms of germination, the hybrid varieties particularly AVT09803 and AVT09001 performed better than the local check (Roma Vf). Roma Vf is not a variety that germinates well in environmental conditions that are hot and wet as it is in Port Harcourt. Also, its long duration to germination means that the risk of seeds damage is high due to prolonged exposure to adverse conditions such as cold and wet soil, and pests and diseases. Hybrids that are bred to adapt to hot/wet conditions, which is not a natural growing condition for tomato, is expected to perform better [10]. Thus, in ideal field conditions for tomato cultivation, Roma Vf can be germinated in situ. Under adverse conditions, AVT09803 and AVT09001 may be pre-germinated.

During the vegetative growth stage, the results of all the parameters that were evaluated, clearly showed that Roma Vf was comparable to AVTO9001 and it out performed the other hybrids. The fact that Roma Vf is a non- hybrid (open pollinated) and a wild variety, ensures that it exhibits its inherent, wild survival tendency to grow fast/ taller than the exotic hybrid varieties that are mostly bred to have reduced plant height, number of nodes and increased number of leaves for efficient leaf function than leaf size [6].

In spite of the fact that Roma Vf had taller plants, more leaves, larger leaf surfaces as compared to the hybrids, the hybrids accumulated more dry matter into different parts of the plants than Roma Vf. This suggests that these hybrids (particularly AVTO9001) may have been bred for increased efficiency in accumulating, utilizing and transport of assimilates. Breeding plants for similar characteristics is a well-known practice [10].

Roma Vf partitioned lower dry matter to the stem which suggests that Roma Vf may be prone to lodging as compared to the hybrids that partitioned higher dry matter to the stem. Thus, if Roma Vf must be grown in the hot/wet conditions as found during the rainy season in the humid tropics of Port Harcourt, it is likely to lodge more readily and thus lead to low productivity. Moreover, Roma Vf is known to have resistance to only fusarium which is a common disease of tomato (www.seedaholic.com/tomato-plum-roma-Vf.html). The exotic hybrid varieties have resistance to more than fusarium and may withstand the unusual conditions common in very humid and hot environment. Therefore, Roma Vf has good vegetative characteristics that suggest that it can grow under hot/wet condition but its productivity is predicted to be poorer than the hybrids because of poor germination, susceptibility to other pest and diseases and low dry matter partitioning characteristics. If Roma Vf has to be grown, extra efforts must be made to improve germination percentage by pre germinating seedlings, filling up missing gaps after establishment, staking of the plant to provide support/ avoid lodging, and nutrients (organic or inorganic) should be added to increase productivity. Suitable and alternative varieties to Roma Vf under the studied weather condition will be AVTO9001 and AVTO9803.

Environmental conditions are well known to influence plant growth and development [6]. Tomato grows best under good moisture conditions (not water logged), in temperatures that ranges between $25-27^{\circ} \mathrm{C}$ [6], conditions that present diurnal temperatures of $25-27^{\circ} \mathrm{C}$ in the day time and $18{ }^{\circ} \mathrm{C}$ at night time. Heavy rains and poor ventilation can also reduce tomato productivity by inhibiting the activity of agents of pollination, reducing the population of the agents of pollination and increasing flower bud and fruits fall [10]. Thus growing tomato under hot conditions can be an adverse environmental condition or stress. The fact that of Roma Vf performed well on the field where it was exposed to excess rain and fluctuating hot conditions as well as in the glasshouse where moisture was adequate and excessive heat was induced but with low pest and disease conditions suggests that Roma Vf can grow under extreme hot conditions as well as under heavy rain conditions. Also, the fact that Roma Vf and AVTO9803 can strive under extreme hot condition implies that these varieties may be important if unprecedented rise in temperature occur as a result of global warming [14].

Environment in this study is not the most important factor limiting the poor production of tomato in the low humid tropics of Port Harcourt and also the ability of those identified varieties to grow under extreme hot conditions implies that they can high temperatures.

\section{Conclusion}

From this research, the lack of tomato production during the hot, high rainfall season in Port Harcourt can be overcome if varieties that can grow well under the prevailing conditions are identified and cultivated. If Roma Vf is chosen for cultivation, provision must be made to fill gaps on the field. Also, germination and seedling growth should be done under controlled environments to hasten germination and reduce seedling lose. Further, Roma Vf may be improved to increase its efficiency to convert resources to food/ dry matter. Farmers and researchers can cultivate the high yielding AVTO9001 and AVTO9803. The fact that Roma Vf and AVTO9803 could grow well under high temperature shows 
that they are more versatile in hot weather and can do well under glasshouse conditions in the Niger Delta region in Nigeria. However, the influence of other factors needs to be properly understood and manipulated to enable a profitable production of tomatoes.

\section{Acknowledgement}

The authors wish to thank Professor D. I. Anyanwu of Plant Science and Biotechnology Department, University of Port Harcourt, for graciously allowing the use of his glasshouse for this study.

\section{References}

[1] van den Berg, H, R. Faulks, H. Fernando Granado, J. Hirschberg, B. Olmedilla, G. Sandmann, S. Southon, and W. Stahl. 2000. The potential for the improvement of carotenoid levels in foods and the likely systemic effects. Journal of the Science of Food and Agriculture: Vol. 80, (7): 880-912.

[2] Stahl, W. and Sies, H. (1996). Lycopene: a biologically important carotenoid for humans. Arch. Biochemistry Biophysics. 366, 1-9.

[3] Rao, A.V., and Agarwal, S., (1999). Role of Lycopene as antioxidant Carotenoids in the prevention of chronic diseases. A Review, Nutrition research, 19(2), 305-323.

[4] Frusciante, L., A. Barone, D. Carputo, M. R. Ercolano, F. dellaRocca, S. Esposito, 2000, Evaluation and use of plant biodiversity for food and pharmaceuticals Evaluation and use of plant biodiversity for food and pharmaceuticals. Fitoterapia, 7: S66-S72

[5] Esminger, H.A., Esminger, E.M., Kolande, E.J., and Robson, K.R. (1994). Food and Nutrition encyclopedia, vol. 2. (Pp. 2111-2114). Florida, USA: CRC press.

[6] Hanson, P, Chen, J.T, Kuo, C.G, Morris, R. and Opena (2001). Tomato production prepared by T. Kalb. World vegetable centre.
[7] IFPRI/PBS, 2007, Assessing the potential economic impact of genetically modified crops in Ghana (http://www.ifpri.org/publication/assessing-potentialeconomic-impact-genetically-modified-crops-ghana-3)

[8] Umeh, V.C, kuku, F.O. Nwanguma, E.I, Adebayo, O.S and Manga (2002). A survey of the insect pests and farmers practices in the cropping of tomato in Nigeria. Tropicultura, Pp 181-188.

[9] FAO (2008). World Crop Production Statistics. Food and Agriculture Organization of United States.

[10] Tijani, A.A, Ayanwale, A.O.S and Baruwa, O.I (2001). Profitability and constrains of tomato production under tropical conditions. International Journal of vegetable science Vol. 16, page 128-134.

[11] Afolabi, C. A., and Ayinde, I.A., 2001. 'Economics of Tomato Production in Yewa North L.G.A of Ogun State, Nigeria' in Agro-Science Journal of Tropical Agriculture, Food, Environment and Extension 2(1), 17-23

[12] Okorie, S.U., Nwanikezi, E.C. and Okoro, C.C., (2004). The quality properties of Tomatoes (Lycopersicum esculentum). As influenced by processing with a chemical preservative and storage.

[13] Alegbejo, M. and Bravo, O. (2006). Moderate Resistance to Tomato Leaf Curl Virus Among Commercial Tomato Cultivars In Northern Nigeria. Journal of Plant Protection Research Vol. 46.

[14] Solomon, S and Qin, D and Manning, M and Alley, RB and Berntsen, T and Bindoff, NL and Chen, $\mathrm{Z}$ and Chidthaisong, A and Gregory, JM and Hegerl, GC and Heimann, $M$ and Hewitson, B and Hoskins, BJ and Joos, F and Jouzel, J and Kattsov, $\mathrm{V}$ and Lohmann, $\mathrm{U}$ and Matsuno, T and Molina, M and Nicholls, $\mathrm{N}$ and Overpeck, $\mathrm{G}$ and Raga, $\mathrm{G}$ and Ramaswamy, V and Ren, J and Rusticucci, $\mathrm{M}$ and Somerville, $\mathrm{R}$ and Stocker, TF and Whetton, $\mathrm{P}$ and Wood, RA and Wratt, D, Technical Summary, Climate Change 2007: The Physical Science Basis. Contribution of Working Group 1 to the Fourth Assessment Report of the Intergovernmental Panel on Climate Change, Cambridge University Press, S Solomon, D Qin, M Manning, M Marquis, KB Averyt, M Tignor, HL Miller and Z Chen (ed), Cambridge, UK and NY, USA, pp. 19-91. ISBN 978-0-521-70596-7 (2007). 